\title{
Immigration's Impact on Bi-lateral Trade Formation: A Social Network Analysis Approach*
}

\author{
Justin Hiraga** , Myong-Sop Pak ${ }^{* * *}$, Jee-Moon Pak ${ }^{* * * *}$
}

\begin{abstract}
In recent years, the proliferation of free trade agreements (FTA) has led to rapid economic boons and political security among nations. This study investigates whether the percentage of expats or permanent foreign residents plays a role in deciding which countries to partner with in bi-lateral FTAs. Previously, the reasons for FTA formation were believed to be primarily based upon economic, geographic, and political reasons. However, through the use of social network analysis, a larger picture can be mapped which allows for a more comprehensive understanding of key players in the current state of FTA formation in relation to the immigrant network that they share between them. More specifically, through computerized social network analysis, centrality can be calculated to determine the key players and the most central immigrant populations. When analyzing both the immigrant centrality in relation to FTA centrality, it becomes evident that there is a high correlation between the two factors. Thus, the findings highlight that immigration trends can be used as a predictor of FTA formation. As a result, it emphasizes the weight of immigration policy on the formation of bi-lateral FTAs.
\end{abstract}

Key Words: Immigration, FTA, social network analysis, centrality

JEL Classification: F22

\footnotetext{
* This work was supported by the National Research Foundation of Korea Grant funded by the Korean Government (NRF-2013S1A3A2055150)

** First Author, Assistant Professor, Dept. of International Business Languages, Seokyung University

*** Corresponding Author, Business School, Sungkyunkwan University

**** Co-author, Researcher, Information Management Research Center, Sungkyunkwan University
} 


\section{Introduction}

Since the inception of the concept of free trade agreements (FTA) came to fruition in the mid 1990's, countries around the globe have become eager to strike a deal with one another and become trade partners. An FTA is a treaty between two or more countries to establish a free trade area where commerce in goods and services can be conducted across their common borders, without tariffs or hindrances, but capital or labor may not move freely. As times are changing, a new wave of "pervasiveness" is ousting economic regionalism is developing (Manfield\& Milner 1999). The World Trade Organization (WTO 2014) states that nearly 300 additional trade agreements were processed and received by the WTO, starting from 1973 to present date. Furthermore, almost every member country of the WTO is connected bilaterally or multilaterally to at least one trade agreement.

An emergence of new research has been developed to determine the motives and reasons for the spread of trade agreements. On one hand, some economists attempt to explain its proliferation to the projected welfare gains and its accompanying ramifications (Yi 1996). On the other hand, political scientists have naturally focuses on the political influences, namely fluctuations in the power dynamics of countries/ governments (Mansfield 1998). Ultimately, the drive for reformation of economy and politics can be attributed to this trending of trade agreements (Heron 2011).

New literature has done a respectable job of documenting the motivations behind the desires to accumulate FTAs in this new age, but lack comprehensive research involving the reasons countries choose one country over another in trade negotiations. A network approach is a new and important aspect to consider when looking into the FTA network. When seeking out FTAs, countries are not blindly choosing partners, but instead are choosing under rational terms. FTA countries can seek political, economic, or any other kind of benefits from their potential partners. Thus, countries are selective in choosing partners, yet there is little literature out there that develops the knowledge base and issue of choice in these matters.

There is one major pitfall in current literature, which is that it is based upon the assumption that each FTA partnership is independent of each other. It does not apply the idea of relativity or interdependence into the equation. As FTAs grow in popularity, it naturally creates a network of interconnections that are overlapping and interdependent. Once FTAs are looked at in a network view, a plethora of external factors can be looked at which can play a role in FTA desirability as a candidate for a bi-lateral trade agreement.

This research attempts to fill this gap in literature by first looking at the existing FTA network for the top countries of the world according to trade volume by social network analysis. Through the same social network analysis, further research into non-economically 
driven networks can be analyzed conjointly. As the world becomes more interconnected and less region specific, naturally the network of immigrants and expats is seen as a by-product of such trends. It has been documented that disruptions in natural immigration patterns can be attributed to FTAs (Massey, Durand, Malone 2002). However, the main purpose of this study is to examine the opposite correlation: Does the percentage of immigrants shared between high trade volume countries increase the likelihood of a bi-lateral FTA?

More specifically, this study aims to achieve the following specific research objectives:

- To determine the network and identify key players within the current FTA network between the top trading countries of the world

- To determine how many immigrants the top trading countries share between them

- To compare the FTA network map with that of the immigrant network map to determine correlation

In this study, the countries chosen to be analyzed were based upon two criteria: international trade volume and those that are not part of the EU. Consequently, the countries used in this study are: China, USA, Japan, Hong Kong, South Korea, Canada, Russia, Singapore, India, Mexico, UAE, and Taiwan. EU countries were omitted as only bi-lateral FTAs were used in determining the network in order to get a more detailed and focused approach. Thus, the units of analysis for this study will be these countries listed along with their respective immigrants.

The remainder of this article's organization is as follows. The next section will provide an overview of literature on immigration and bi-lateral trade implications from various perspectives including SNA. This section also includes extant literature that has looked at bi-lateral trade formation as merely political or economical in cause. Then an overview of the databases used and its associated measurement techniques will be provided. Results of the study and then the implications are set forth, followed by a conclusion.

\section{Literature Review}

\subsection{Immigration's Relationship with International Trade}

In the $20^{\text {th }}$ century there has been a rapid rise in immigration and emigration among countries globally. Nowadays approximately $4 \%$ of the world's population are considered to be expats, or permanent residents of a different country from their birth. During this time, 
the global economy has seen a boon as global trade has increased from approximately $6 \%$ of GDP in 1950 to almost $20 \%$ of GDP in 2004. Additionally, almost non-existent foreign direct investment (FDI) from the 1950's, has risen dramatically to over \$US 1.3 trillion in 2000 (UNCTAD 2001).

Coinciding growth between international trade, foreign investment, and immigration advocates the idea that they are related. Mounting substantiation backs the indication that immigration/emigration has a positive impact on international trade between countries linked through immigrant populations. Exemplary studies have been done by Dunleavy and Hutchinson (1999, 2001), Girma and Yu (2000), Gould (1994) and Head and Ries (1997). Some of the linkages immigration creates stems from their abilities to connect host and home. These links or bonds meld through language, demand for goods, business networks, and extensive cultural understanding and sensitivity to navigate both markets and financial institutions. Traditional economic analysis of immigration primarily deals with the ideas of labor market effects (Borjas 1994, 1995). Trade between two countries exposes each other to the formal institutions regulations, standards of product and labor, and manners of doing business. The accumulation of shared experiences often fosters convergence of institutions between host and home countries. In turn, this convergence reduces risks and uncertainties in bi-lateral trade (Mansfield and Reinhardt 2008).

The impact of immigration on international trade can be attributed to many different channels. Five specific channels are identified that may play a factor in affecting international trade between host and home countries of immigrants. Immigration/ emigration can affect the establishment of networks, average national income, foreign direct investment (FDI), the country's ratio of dependence, and a countries willingness towards foreign transactions especially bi-lateral free trade agreements.

Saxenian (2002) claims that immigrants are responsible for building "social networks that span national boundaries and facilitate flows of capital, skill, and technology. In so doing, they are creating transnational communities $\cdots$ that allow local producers to participate in an increasing global community" (Saxenian, 2002; pp. 28). A historical analysis of immigrant networks is further explored by Rauch $(1999,2001)$. Furthermore, though this channel may promote trade, it can also be trade-diverting. Parente and Prescott (2000) explained how vested interests may impede competition and consequently economic change. This suggests that these social networks may obstruct trade expansion by creating barriers for entry. Furthering upon the idea of the building of networks due to immigrant populations, it can be noted that it can also promote shared sociocultural values and market preferences between the host and home countries. Social diffusion can be derived from network ties (Burt, 1987; Mizruchi 1990). Moreover, economic trade is not only embedded in social relationships, but consequently spawn new growth in social networks and relations 
(Barber 1995). When two countries engage in trade with each other, they correspondingly also make an exchange of social values and cultural preferences. Information produced by common business networks include market opportunities, product standards, prices, and a local knowledge of each other's markets between host and home countries, which can easily be converted into direct bilateral trade (White, 2002). Share information also allows for a better understanding of each other's behaviors as they can be predicted easier, which in turn fosters the growth in mutual trust (Guiso, 2004).

A common theme within international economics theory is that immigration affects income levels and consequently can affect the flow of trade. As opposed to traditional views, new evidence suggests that immigration does not always reduce wages in the host country. Friedberg and Hunt (1995) suggest that wages and income are not negatively impacted by the immigration of workers from one country to another.

The visible remnants of immigrant populations are oftentimes seen by the public as specific areas which have become dominated by a particular immigrant population, such as Chinatown. However, recent studies reveal the fallacy in this impression. Saxenian (2002) proposes that economic international investment is driven by increased immigrant communities and that this investment flows well past the specific immigrant territories and communities. Furthering this research, Clausing (2000) determined that a strong FDI is positively correlated to international trade.

In general, immigrant populations tend to be younger than the average age compared to those of the host country. Host countries that have high-level incomes on average host immigrants who are disposed to having higher level of children compared to that of the host country's native population. Consequently, a high immigrant population will change the demographics of the host country to one of a younger labor force which affects many facets of economics, one being imports and exports. Coppel, Dumont and Visco (2001) have made the connection between an aging population and the economic burden that such a population has on its own economy. Essentially, Cooper (2002) and the OECD (2002), state that economies that remain stagnant or slow in growth have lower trade volumes than those of emerging or vivacious economies. Thus, it is worth acknowledging that if immigration can mitigate the problem of an ageing working population, then it could very well be predictable that it can in turn, boost international trade.

The last conjecture is that countries with lower government-induced barriers to trade will have a higher overall trade volume than those countries who do not. Not much literature deals with the idea of immigrant populations on the more openness a government is to trade. However, one could assume that a more open attitude toward foreign immigration would coincide with a more open attitude toward trade international markets. 
After considering these arguments, immigration can be seen to play a big part in the diffusion of similar values, social trust, information flow, and the convergence of institutions. Along with immigration's effect on income levels, FDI, work-force populations, and governmental views on open trade, these can all lead to increased bi-lateral trade and a desirable partnership. Bilateral trade is initially looked at as a form of economic exchange which is strongly affected by the cultural conceptions of each partner participating in such trade (Zelizer 2003). As a result, this shows that countries make a decision on who they will choose as a partner based on shared sociocultural understanding because sharing common values and cultural awareness promotes trust, reduces volatility, and helps facilitate easier communication while negotiating deals. Subsequently, under the same flow of logic one could proclaim that shared sociocultural values and ideas enable and expedite bilateral trade agreements.

Hence, these arguments suggest that countries that share an immigration population between them within the global trade network are likely to develop more bilateral trade. Accordingly, the hypothesis proposed is as follows:

Hypothesis: Countries with a higher number of immigrants from a specific country are more likely to form bi-lateral trade agreements with said country.

\subsection{Methodology}

This study limits its focus to the FTA agreement relationships between the world's countries. Countries were selected and the sample was narrowed down according to two factors. The first factor was international trade volume. As this study aims to link a country's immigration/emigration with the FTA network, only top trading countries were of interest, since they compose a considerable proportion of the FTA network. Thus, the top 20 countries based upon international trade volume were selected to be analyzed as part of this study. Secondly, these top countries were further narrowed down to exclude countries that were part of the EU trade bloc. This is due to the nature of a trade bloc consisting of multiple countries and immigrants of different nations. In the attempt to make connections between immigrant populations and bi-lateral FTAs, including trade bloc countries within this study would not fit in the model. For example, comparing the relationship of French (EU) immigrants in Korea since the EU has an FTA with Korea would not be an accurate detailed account of the reality of the situation. The EU has many different countries within it, making it difficult to determine which immigrants make a contributing factor and thus diluting the message. For that reason, EU countries were omitted from this study. As a 
result, this study focuses on China, the USA, Hong Kong, South Korea, Canada, Russia, Singapore, India, Mexico, the UAE, and Taiwan.

The study is a two part study as it compares the FTA network with that of the immigrant network. The FTA network can be defined as the interlocking bi-lateral FTAs that are shared among them. Information of FTAs were retrieved from the WTO database. [Table 1] is matrix-like, with several rows and columns which shows the countries used in the analysis of the FTA network for this study along with each countries' FTA partner. The blacked out cells within the table represent an FTA partnership.

Table 1.

Top Trading Countries within the FTA Network 2014

\begin{tabular}{c|c|c|c|c|c|c|c|c|c|c|c|c}
\hline & CN & US & JP & HK & KR & CA & RU & SG & IN & MX & AE & TW \\
\hline CN & xxxxx & & & & & & & & & & & \\
\hline US & & xxxxx & & & & & & & & & & \\
\hline JP & & & xxxxx & & & & & & & & & \\
\hline HK & & & & xxxxx & & & & & & & & \\
\hline KR & & & & xxxxx & & & & & & & \\
\hline CA & & & & & & xxxxx & & & & & & \\
\hline RU & & & & & & xxxxx & & & & & \\
\hline SG & & & & & & & xxxxx & & & & \\
\hline IN & & & & & & & & & $\mathrm{xxxxx}$ & & & \\
\hline MX & & & & & & & & & & $\mathrm{xxxxx}$ & & \\
\hline AE & & & & & & & & & & & $\mathrm{xxxxx}$ & \\
\hline TW & & & & & & & & & & & & $\mathrm{xxxxx}$ \\
\hline
\end{tabular}

The second part of the study involves building the immigrant network between the countries represented in Table 1. This table includes six different categories: host country, immigrant total, immigrant number, percentage, and rating. Host country represents each country in table 1 . The value within the "Immigrant Total" category is the total number of immigrants in from each of the countries listed in this study, not the total number of immigrants within host country. This is done as only the relationships from within this network are of interest in this study. Furthermore, the definition of immigrant is a permanent resident or resident with a valid working visa within host country. This definition excludes undocumented or illegal immigrants. The next category is immigrant country which is defined as the country of origin for immigrants residing in their host country (category 1). Immigrant number is the total number of documented/estimated 
immigrants of each corresponding home country (category 3). The majority of immigrant data comes from each countries' population consensus from years 2010-2014. In certain cases the exact number of immigrants were omitted due to a lack of verifiable data. However, in these cases due to circumstantial evidence and context it is estimated to be less than $1 \%$ of the total immigrant population. The percentage category was created in order to show the relativity of immigrants in relation to each other country. This relative percentage gives more weight and can more easily depict relationships rather than when compared to an absolute percentage (ie: percentage of total population). Thus, a relative percentage was utilized for this study. Lastly, each percentage was converted to a scale of 1-4, 1 being the least weight and 4 being the highest weight. This was done in order to further simplify the weight scale from a percentage base to an ordinal ranking system. The ranking system was determined by a stepped percentage scale. $0-10 \%=1,10-30 \%=2,30-60 \%=3,60-100 \%=$ 4. The choice to make the scale stepped vs equally distributed was adopted in order to help further disseminate the lower percentages from each other, while allowing for the much less common high weights to be clustered together. Overall, it allows for a more even distribution of variant weights to be depicted and analyzed later on.

Table 2.

Immigrant Network

\begin{tabular}{c|c|c|c|c|c}
\hline Host Country & $\begin{array}{c}\text { Immigrant } \\
\text { Total }\end{array}$ & Immigrant Country & Immigrant Number & Percentage & Rating \\
\hline China & 768,948 & USA & 71,493 & $9.30 \%$ & 1 \\
\hline & & Japan & 66,159 & $8.60 \%$ & 1 \\
\hline & & Hong Kong & 234,829 & $30.54 \%$ & 3 \\
\hline & & South Korea & 120,750 & $15.70 \%$ & 2 \\
\hline & & Canada & 19,990 & $2.60 \%$ & 1 \\
\hline & & Russia & 15,393 & $2.00 \%$ & 1 \\
\hline & & Singapore & 20,000 & $2.60 \%$ & 1 \\
\hline & & India & 15,051 & $1.96 \%$ & 1 \\
\hline & & Mexico & 20,000 & $2.60 \%$ & 1 \\
\hline & & UAE & 15,000 & $1.95 \%$ & 1 \\
\hline & & Taiwan & 170,283 & $22.14 \%$ & 2 \\
\hline & $18,586,845$ & China & $1,651,511$ & $8.89 \%$ & 1 \\
\hline & & Japan & 314,042 & $1.69 \%$ & 1 \\
\hline & & Hong Kong & 219,872 & $1.18 \%$ & 1 \\
\hline & & South Korea & $1,095,084$ & $5.89 \%$ & 1 \\
\hline
\end{tabular}




\begin{tabular}{|c|c|c|c|c|c|}
\hline Host Country & $\begin{array}{c}\text { Immigrant } \\
\text { Total }\end{array}$ & Immigrant Country & Immigrant Number & Percentage & Rating \\
\hline & & Canada & 787,542 & $4.24 \%$ & 1 \\
\hline & & Russia & 398,086 & $2.14 \%$ & 1 \\
\hline & & Singapore & 5,347 & $0.03 \%$ & 1 \\
\hline & & India & $1,855,705$ & $9.98 \%$ & 1 \\
\hline & & Mexico & $11,691,632$ & $62.90 \%$ & 4 \\
\hline & & UAE & 200,000 & $1.08 \%$ & 1 \\
\hline & & Taiwan & 368,024 & $1.98 \%$ & 1 \\
\hline \multirow[t]{11}{*}{ Japan } & $1,332,499$ & China & 652,555 & $48.97 \%$ & 3 \\
\hline & & USA & 48,357 & $3.63 \%$ & 1 \\
\hline & & Hong Kong & 35,535 & $2.67 \%$ & 1 \\
\hline & & South Korea & 530,046 & $39.78 \%$ & 3 \\
\hline & & Canada & 9,006 & $0.68 \%$ & 1 \\
\hline & & Russia & 7,295 & $0.55 \%$ & 1 \\
\hline & & Singapore & 2,135 & $0.16 \%$ & 1 \\
\hline & & India & 21,653 & $1.62 \%$ & 1 \\
\hline & & Mexico & 2,123 & $0.16 \%$ & 1 \\
\hline & & UAE & 1,021 & $0.08 \%$ & 1 \\
\hline & & Taiwan & 22,773 & $1.71 \%$ & 1 \\
\hline \multirow[t]{11}{*}{ Hong Kong } & $6,419,561$ & China & $6,364,439$ & $99.14 \%$ & 4 \\
\hline & & USA & $*$ & $0.00 \%$ & 1 \\
\hline & & Japan & 21,297 & $0.33 \%$ & 1 \\
\hline & & South Korea & 5,209 & $0.08 \%$ & 1 \\
\hline & & Canada & $*$ & $0.00 \%$ & 1 \\
\hline & & Russia & $*$ & $0.00 \%$ & 1 \\
\hline & & Singapore & $*$ & $0.00 \%$ & 1 \\
\hline & & India & 28,616 & $0.45 \%$ & 1 \\
\hline & & Mexico & $*$ & $0.00 \%$ & 1 \\
\hline & & UAE & $*$ & $0.00 \%$ & 1 \\
\hline & & Taiwan & $*$ & $0.00 \%$ & 1 \\
\hline \multirow[t]{5}{*}{ South Korea } & 388,881 & China & 299,000 & $76.89 \%$ & 4 \\
\hline & & USA & 41,789 & $10.75 \%$ & 2 \\
\hline & & Japan & 17,068 & $4.39 \%$ & 1 \\
\hline & & Hong Kong & $*$ & $0.00 \%$ & 1 \\
\hline & & Canada & 10,378 & $2.67 \%$ & 1 \\
\hline
\end{tabular}




\begin{tabular}{|c|c|c|c|c|c|}
\hline Host Country & $\begin{array}{c}\text { Immigrant } \\
\text { Total }\end{array}$ & Immigrant Country & Immigrant Number & Percentage & Rating \\
\hline & & Russia & 5,230 & $1.34 \%$ & 1 \\
\hline & & Singapore & 391 & $0.10 \%$ & 1 \\
\hline & & India & 3,504 & $0.90 \%$ & 1 \\
\hline & & Mexico & 338 & $0.09 \%$ & 1 \\
\hline & & UAE & $*$ & $0.00 \%$ & 1 \\
\hline & & Taiwan & 11,183 & $2.88 \%$ & 1 \\
\hline \multirow[t]{11}{*}{ Canada } & 90,841 & China & 33,018 & $36.35 \%$ & 3 \\
\hline & & USA & 9,414 & $10.36 \%$ & 2 \\
\hline & & Japan & 1,307 & $1.44 \%$ & 1 \\
\hline & & Hong Kong & 1,093 & $1.20 \%$ & 1 \\
\hline & & South Korea & 5,308 & $5.84 \%$ & 1 \\
\hline & & Russia & 1,962 & $2.16 \%$ & 1 \\
\hline & & Singapore & 348 & $0.38 \%$ & 1 \\
\hline & & India & 28,943 & $31.86 \%$ & 3 \\
\hline & & Mexico & 4,032 & $4.44 \%$ & 1 \\
\hline & & UAE & 4,253 & $4.68 \%$ & 1 \\
\hline & & Taiwan & 1,163 & $1.28 \%$ & 1 \\
\hline \multirow[t]{11}{*}{ Russia } & 873,000 & China & 300,000 & $34.36 \%$ & 3 \\
\hline & & USA & 30,000 & $3.44 \%$ & 1 \\
\hline & & Japan & 3,000 & $0.34 \%$ & 1 \\
\hline & & Hong Kong & $*$ & $0.00 \%$ & 1 \\
\hline & & South Korea & 500,000 & $57.27 \%$ & 3 \\
\hline & & Canada & $*$ & $0.00 \%$ & 1 \\
\hline & & Singapore & $*$ & $0.00 \%$ & 1 \\
\hline & & India & 40,000 & $4.58 \%$ & 1 \\
\hline & & Mexico & $*$ & $0.00 \%$ & 1 \\
\hline & & UAE & $*$ & $0.00 \%$ & 1 \\
\hline & & Taiwan & $*$ & $0.00 \%$ & 1 \\
\hline \multirow[t]{6}{*}{ Singapore } & 3079233 & China & $2,707,200$ & $87.92 \%$ & 4 \\
\hline & & USA & 15,000 & $0.49 \%$ & 1 \\
\hline & & Japan & 23,583 & $0.77 \%$ & 1 \\
\hline & & Hong Kong & $*$ & $0.00 \%$ & 1 \\
\hline & & South Korea & 16,650 & $0.54 \%$ & 1 \\
\hline & & Canada & $*$ & $0.00 \%$ & 1 \\
\hline
\end{tabular}




\begin{tabular}{|c|c|c|c|c|c|}
\hline Host Country & $\begin{array}{c}\text { Immigrant } \\
\text { Total }\end{array}$ & Immigrant Country & Immigrant Number & Percentage & Rating \\
\hline & & Russia & $*$ & $0.00 \%$ & 1 \\
\hline & & India & 316,800 & $10.29 \%$ & 2 \\
\hline & & Mexico & $*$ & $0.00 \%$ & 1 \\
\hline & & UAE & $*$ & $0.00 \%$ & 1 \\
\hline & & Taiwan & $*$ & $0.00 \%$ & 1 \\
\hline \multirow[t]{11}{*}{ India } & 36369 & China & 4,000 & $11.00 \%$ & 2 \\
\hline & & USA & 15,000 & $41.24 \%$ & 3 \\
\hline & & Japan & 7,132 & $19.61 \%$ & 2 \\
\hline & & Hong Kong & $*$ & $0.00 \%$ & 1 \\
\hline & & South Korea & 8,337 & $22.92 \%$ & 2 \\
\hline & & Canada & 1,100 & $3.02 \%$ & 1 \\
\hline & & Russia & 300 & $0.82 \%$ & 1 \\
\hline & & Singapore & 500 & $1.37 \%$ & 1 \\
\hline & & Mexico & $*$ & $0.00 \%$ & 1 \\
\hline & & UAE & $*$ & $0.00 \%$ & 1 \\
\hline & & Taiwan & $*$ & $0.00 \%$ & 1 \\
\hline \multirow[t]{11}{*}{ Mexico } & 766100 & China & 6,655 & $0.87 \%$ & 1 \\
\hline & & USA & 738,103 & $96.35 \%$ & 4 \\
\hline & & Japan & 4,485 & $0.59 \%$ & 1 \\
\hline & & Hong Kong & $*$ & $0.00 \%$ & 1 \\
\hline & & South Korea & 5,518 & $0.72 \%$ & 1 \\
\hline & & Canada & 7,943 & $1.04 \%$ & 1 \\
\hline & & Russia & 1,396 & $0.18 \%$ & 1 \\
\hline & & Singapore & $*$ & $0.00 \%$ & 1 \\
\hline & & India & 2,000 & $0.26 \%$ & 1 \\
\hline & & UAE & $*$ & $0.00 \%$ & 1 \\
\hline & & Taiwan & $*$ & $0.00 \%$ & 1 \\
\hline \multirow[t]{7}{*}{ UAE } & 2038400 & China & 180,000 & $8.83 \%$ & 1 \\
\hline & & USA & 40,000 & $1.96 \%$ & 1 \\
\hline & & Japan & 4,000 & $0.20 \%$ & 1 \\
\hline & & Hong Kong & $*$ & $0.00 \%$ & 1 \\
\hline & & South Korea & 3,100 & $0.15 \%$ & 1 \\
\hline & & Canada & 40,000 & $1.96 \%$ & 1 \\
\hline & & Russia & 18,000 & $0.88 \%$ & 1 \\
\hline
\end{tabular}




\begin{tabular}{c|c|c|c|c|c}
\hline Host Country & $\begin{array}{c}\text { Immigrant } \\
\text { Total }\end{array}$ & Immigrant Country & Immigrant Number & Percentage & Rating \\
\hline & & Singapore & 2,100 & $0.10 \%$ & 1 \\
\hline & & India & $1,750,000$ & $85.85 \%$ & 4 \\
\hline & & Mexico & 1,200 & $0.06 \%$ & 1 \\
\hline Taiwan & 182,466 & Taiwan & $*$ & $0.00 \%$ & 1 \\
\hline & & China & 128,744 & $70.56 \%$ & 4 \\
\hline & & USA & 9,645 & $5.29 \%$ & 1 \\
\hline & & Japan & 11,661 & $6.39 \%$ & 1 \\
\hline & & Hong Kong & 21,218 & $11.63 \%$ & 2 \\
\hline & & South Korea & 3,496 & $1.92 \%$ & 1 \\
\hline & & Canada & 2,089 & $1.14 \%$ & 1 \\
\hline & & Russia & 2,400 & $1.32 \%$ & 1 \\
\hline & & Singapore & 1,286 & $0.70 \%$ & 1 \\
\hline & & India & 1,927 & $1.06 \%$ & 1 \\
\hline & & Mexico & $*$ & $0.00 \%$ & 1 \\
\hline
\end{tabular}

*Exact number was negligible, but estimated at $<1 \%$

\section{Results}

Examining the idea of immigration and bi-lateral trade agreements from the perspective of SNA may lend insight to their relationship. In analyzing both structures of countries, the FTA networks shared between and that of the immigrant network, measures of centrality have been suggested as alternate measures of power and influence within networks. The idea of power through centrality comes from the concept that organizations or nodes positioned within the center of a network are more powerful than other organizations or nodes that lie along the peripheral network structure (Brass and Burkhardt 1993).This is due to the idea that power accumulates and flows toward the organizations or nodes at the center of the network because of their relative access to information and resources compared to the others. Analysts who study networks can quantify and measure power in the network using the idea of degree centrality. Degree centrality can be divided into two distinct parts, 'in' and 'out'. On one hand, 'In' centrality (in-degree centrality) encapsulates the centrality of nodes through incoming links. On the other hand, 'Out' centrality (out-degree centrality) encapsulates the centrality of nodes through outgoing 
links. Nodes with considerable out-centrality have the ability to exchange or interact more with several other nodes and consequently are much more influential or powerful within the network (Brass and Burkhardt 1993). Thus, when analyzing the immigrant network structure this study will focus much more on the 'out' degree of centrality rather than the 'in' degree of centrality. However, for the analysis of solely the FTA network, the in-degree centrality is the only part that is examined.

This study contained two parts in its analysis: the FTA network and the immigration network shared between such countries. The computer program "Netminer" was used in the analysis and visualization of data for both social network analysis. In comparison of both visualizations and comparison of data sets returned from analysis attempt to reveal relationships between both factors in this study.

The first analysis dealt with the FTA network and its centrality in an unweighted relationship. Netminer's analysis of the FTA network based upon each country's bi-lateral FTA agreements with each other is depicted in Figure 1. This specific pictogram displays the unweighted centrality relationships between each country. One main network is revealed containing all the countries in this study except for Russia which remains as an outlier. The interior nodes are China, Singapore, Korea, and USA. When visualized in a concentric ring pictogram (Figure 2), the network clearly shows that the countries with the most centrality China, Singapore, and the USA, with China being the most central countries. Conversely, the centrality positions of Mexico, Canada, UAE, Hong Kong, Taiwan, and Japan are less central to the network compared to China, Singapore, and the USA.

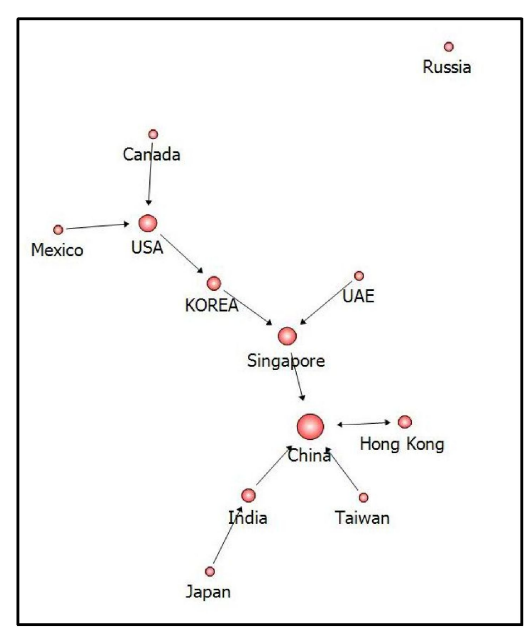

Figure 1.

Linear FTA Network (Centrality)

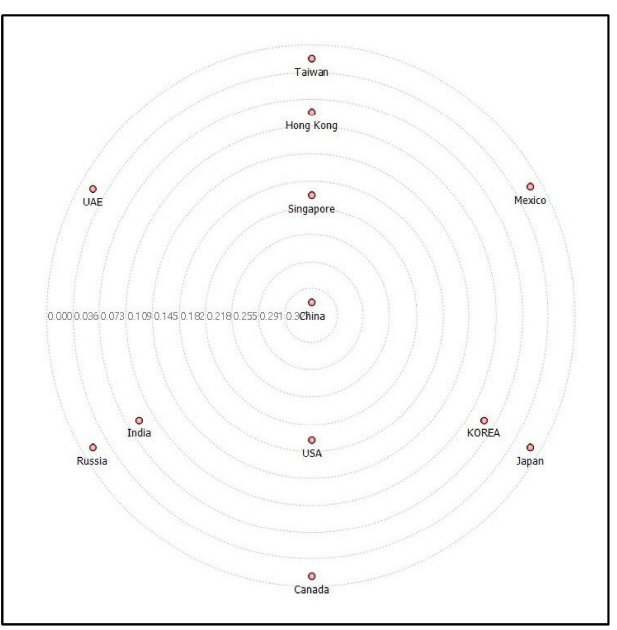

Figure 2. Concentric FTA Network Centrality 
The second analysis dealt with the immigrant network shared between the countries examined in this study. The centrality can be measured using Netminer which calculated and provided the exact degrees of centrality between each country. This network added an additional dimension to the network as the relationship between each country was measured into 2 degrees: in-degree and out degree centrality as previously mentioned. Figure 3 and Figure 4 depict this weighted centrality showing the degrees of which each country is connected to the other in terms of in-degree and out-degree centrality. Figure 3 is a random generated visualization; however, Figure 4 lays out the immigrant centrality in a more discerning manner as a circular diagram. In Figure 4, the weights are shown as 1-4, with 1 being the smallest value and 4 being the largest value. Upon observation, the immigration flow outward (out-degree) and the immigrant flow inward (in-degree) become more evident. Also, the observation that China and Korea are centralized in Figure 5 supports the notion that Chinese and Korean immigrants are more centrally spread out among studied countries and with a more even distribution.

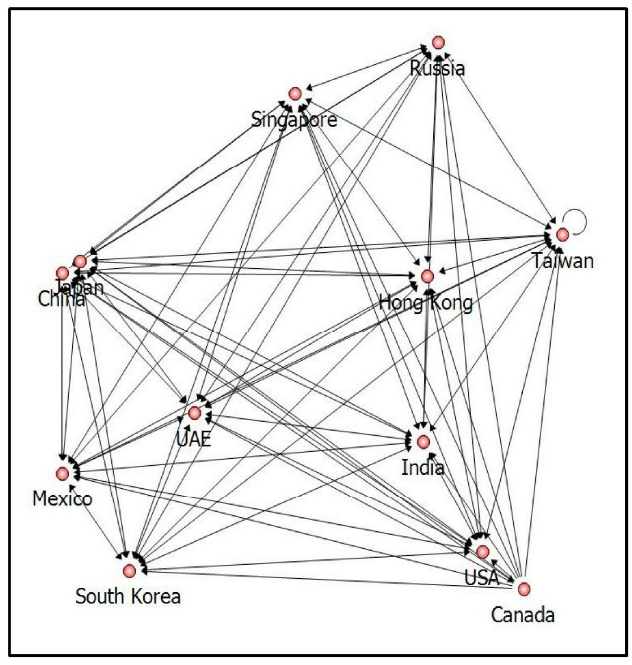

Figure 3.

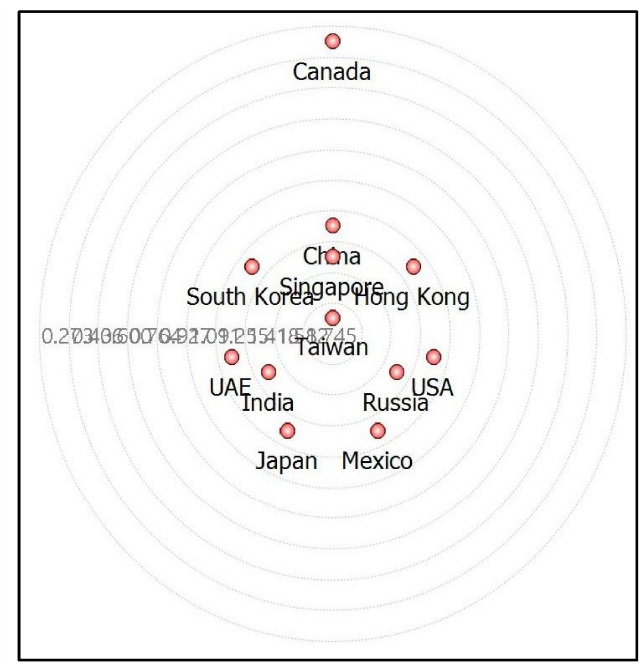

Figure 4.

Immigrant Network Centrality (Concentric) 


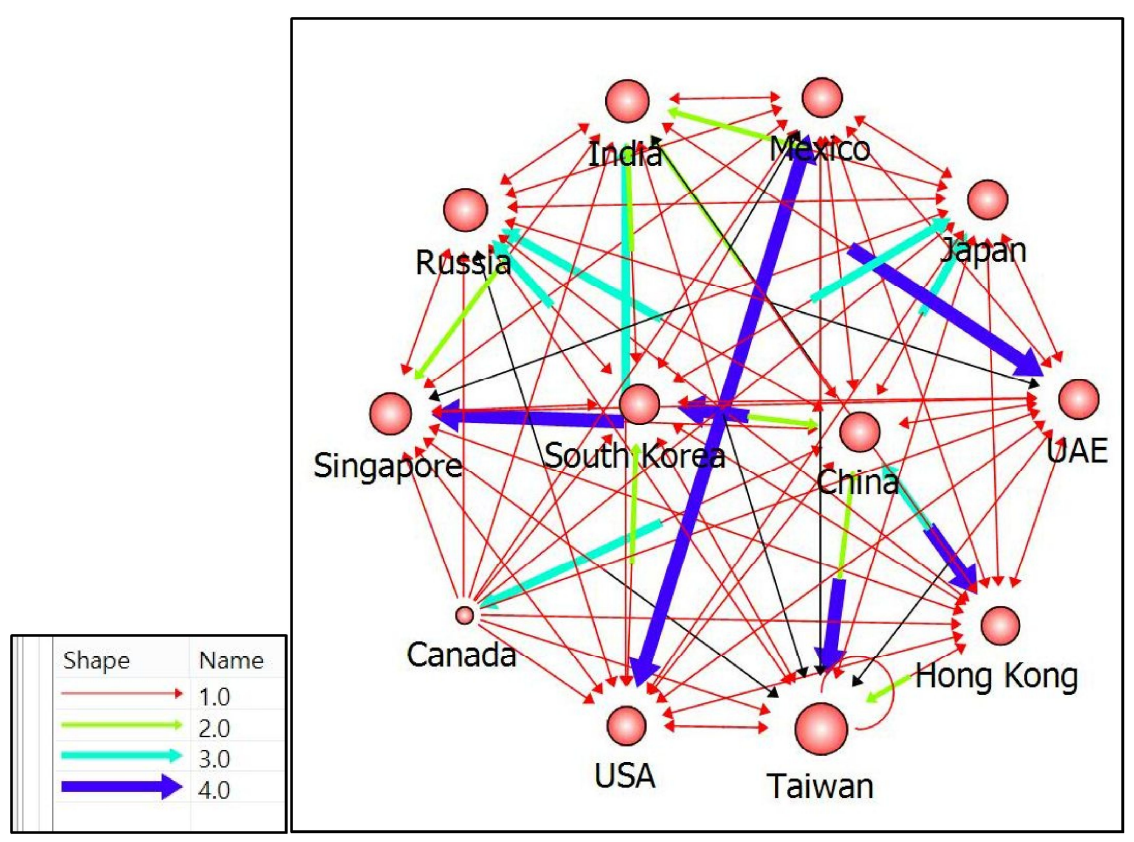

Figure 5.

Immigrant Network Centrality (Circular-Weighted)

Analysis through Netminer not only produces visual information in the forms of visualizations and diagrams, but also through tables of information. For Table 3: the important value here is the in-degree centrality. Accordingly, in-degree is a count of the number of ties directed to the node and out-degree is the number of ties that the node directs to others. When ties are associated to some positive aspects such as friendship or collaboration, in-degree is often interpreted as a form of popularity, and out-degree as gregariousness. It should be noted that the highest in-degree value is that of China, which can be translated to mean that it has the highest connectivity within the FTA network. The USA and Singapore are tied for the 2nd highest in-degree centrality, while Hong Kong, South Korea, and India tie for 3rd, while Japan, Canada, Russia, Mexico, UAE, and Taiwan.

\section{Table 3.}

FTA Network Centrality

\begin{tabular}{c|c|c}
\hline & In-Degree Centrality & Out-Degree Centrality \\
\hline China & 0.363636 & 0.090909 \\
\hline USA & 0.181818 & 0.090909 \\
\hline
\end{tabular}




\begin{tabular}{c|c|c}
\hline & In-Degree Centrality & Out-Degree Centrality \\
\hline Japan & 0 & 0.090909 \\
\hline Hong Kong & 0.090909 & 0.090909 \\
\hline South Korea & 0.090909 & 0.090909 \\
\hline Canada & 0 & 0.090909 \\
\hline Russia & 0 & 0 \\
\hline Singapore & 0.181818 & 0.090909 \\
\hline India & 0.090909 & 0.090909 \\
\hline Mexico & 0 & 0.090909 \\
\hline UAE & 0 & 0.090909 \\
\hline Taiwan & 0 & 0.090909 \\
\hline
\end{tabular}

In the analysis of the immigrant network, nodes with considerable out-centrality have the ability to exchange or interact more with several other nodes and consequently are much more influential or powerful within the network as previously explained. Therefore the out-degree centrality's value is of much more concern in evaluating its influence on the network. Out-degree in this aspect reflects the number of immigrants who have emigrated out of their home countries and now reside in a host country. For example, in Table 4, the out-degree centrality value of 2.727273 reflects the amount of Chinese immigrants living in other countries than China. Here it can be noted that China has by far a larger margin of out-degree centrality than the rest of the countries in this study. Second is the USA (1.63634), followed by South Korea (1.545455) and India (1.545455). The countries with the lowest out-degree centrality are Canada, Russia, Singapore, UAE, and Taiwan.

A country in the network that receives many ties, is characterized as prominent (in-degree centrality). The basic idea is that many others seek to direct ties to them and so this may also be regarded as a measure of importance. So, one key observation is the relatively high value of in-degree centrality of Taiwan (1.909091) which is almost 25\% higher than the second highest of both India and Russia (1.545455) in Table 4.

Table 4.

Immigrant Network Centrality

\begin{tabular}{c|c|c}
\hline & In-Degree Centrality & Out-Degree Centrality \\
\hline China & 1.363636 & 2.727273 \\
\hline USA & 1.272727 & 1.636364 \\
\hline Japan & 1.363636 & 1.090909 \\
\hline Hong Kong & 1.272727 & 1.272727 \\
\hline
\end{tabular}




\begin{tabular}{c|c|c}
\hline & In-Degree Centrality & Out-Degree Centrality \\
\hline South Korea & 1.363636 & 1.545455 \\
\hline Canada & 0.272727 & 1 \\
\hline Russia & 1.545455 & 1 \\
\hline Singapore & 1.454545 & 1.545455 \\
\hline India & 1.545455 & 1.272727 \\
\hline Mexico & 1.363636 & 1 \\
\hline UAE & 1.363636 & 1 \\
\hline Taiwan & 1.909091 &
\end{tabular}

An analysis of the descriptive statistics derived from the in-degree and out-degree of both FTA network (A \& B) and the in-degree and out-degree of the immigration network can be seen in Table 5. The table's core information lies in the calculated mean, standard deviation, and sample size accordingly. After running the key statistics through Pearson Product Moment Correlation (PPMC) correlations could be determined (Table 6). Accordingly, it can be noted that the correlation is significant at the 0.01 level (2-tailed) for out-degree centrality of the immigration network and in-degree centrality for the FTA network with a .850 Pearson correlation coefficient. This indicates a high correlation between highly centralized countries in terms of out-going immigrants and how well connected they are in FTA bi-lateral agreements.

\section{Table 5.}

Descriptive Statistics

\begin{tabular}{|l|r|r|r|}
\hline & \multicolumn{1}{|c|}{ Mean } & Std. Deviation & \multicolumn{1}{|c|}{$N$} \\
\hline (A) In-FTA & .083333 & .1127374 & 12 \\
(C) In-Immi & 1.340909 & .3780711 & 12 \\
(B) Out-FTA & .083333 & .0262432 & 12 \\
(D) Out-Immi & 1.340909 & .4996243 & 12 \\
\hline
\end{tabular}


Table 6.

Correlations

\begin{tabular}{|ll|r|r|r|r|}
\hline & & (A) In-FTA & (C) In-Immi & (B) Out-FTA & (D) Out-Immi \\
\hline (A) In-FTA & Pearson Correlation & 1 & .066 & .233 & $.850^{20}$ \\
& Sig. (2-tailed) & & .838 & .467 & .000 \\
& $N$ & 12 & 12 & 12 & 12 \\
\hline (C) In-Immi & Pearson Correlation & .066 & 1 & -.170 & .053 \\
& Sig. (2-tailed) & .838 & & .597 & .871 \\
& $\mathrm{~N}$ & 12 & 12 & 12 & 12 \\
\hline (B) Out-FTA & Pearson Correlation & .233 & -.170 & 1 & .215 \\
& Sig. (2-tailed) & .467 & .597 & & .502 \\
& $\mathrm{~N}$ & 12 & 12 & 12 & 12 \\
\hline (D) Out-Immi & Pearson Correlation & $.850^{2 \pi}$ & .053 & .215 & 1 \\
& Sig. (2-tailed) & .000 & .871 & .502 & \\
N & 12 & 12 & 12 & 12 \\
\hline
\end{tabular}

**. Correlation is significant at the 0.01 level (2-tailed).

\section{Conclusion}

This study investigated the bi-lateral FTA structure of high volume trading countries that are non-bloc countries (ie: non-EU) in relation to their shared immigrant/emigrant network shared between them. After collecting data and applying correlation analysis, their relationship upon each other was examined through the framework of network centrality. Consequently, this article has two major contributions. The first contribution is through its methodology and the second is a more functional broad contribution.

Looking from the side of a methodological standpoint, this study utilized social network analysis (SNA) to shed light on a key question "Why are FTA's formed?", on a much more macro-economic point of view. Previous studies focused more on individual cases and individual 'actors'. However, by utilizing and applying a network point of view, it can become more observable how individuals interact with each other and how this variable influences individual actions. By having social network analysis as a tool, such ideas can focus on the patterns of relationships among various individuals or nodes within a 
network. This analysis also extends research analysis by exemplifying how SNA can be used in international trade analysis research, especially if one wants to observe it from a macro-viewpoint.

The second contribution pertains more to the aim of this study. Through SNA it has been demonstrated that while bi-lateral trade agreements have become more common, bi-lateral trade agreements are not happening independently from one another. There is a linking force that factors in the creation of such agreements between countries. One such correlated factor is the intricate immigrant network shared between them. Strong correlations reside between a country's immigrant population and who they choose to be partners with in trade agreements. Countries with high degrees of in-degree centrality within the FTA network were connected more with countries that had high-degrees of out-degree centrality in their immigration network.

These findings can lead to a wealth of broad managerial implications, especially within the realm of public policy. As FTAs and bi-lateral trade agreements become more sought after, countries lobbying to become candidates are desperate to become part of this ever-growing network. In doing so, they spend money on infrastructure, public projects, and so on. However, identifying immigrant populations as a factor in FTA creation, could lead to countries paying more attention to policies both immigration and emigration. Furthermore, countries could even go so far as to favor one countries immigrants over others in hopes to favorably affect certain countries' ties with each other in hopes of encouraging trade agreements. Thus, within the realm of public policy many insights have been gained that could be contributing factors in future trade agreements.

This study, while providing some key insights into FTA/immigration relationships in a global network, has limitations that indicate that its results should be interpreted with restraint. The first limitation deals with the sample used for this study. Ideally, to get a more full scope and more statistically significant result, the sample size of study should be larger and even to the extent to cover all countries that hold bi-lateral trade with one another. Future studies could even include bloc countries such as the EU though sorting out the immigrant networks between a single country and the entire EU could prove to be a complex ordeal. Another limitation deals with the fact that this study was essentially a snapshot of current time in 2014. Due to the fact that FTAs and trade agreements did not all happen simultaneously and immigrant populations are constantly shifting leads to the awareness that this study would prove more useful if immigrant population 'snapshots' could be observed for each trade agreement at that specific time. In other words, each FTA agreement would have a different time stamp and a different set of data for the immigrant network.

This current study can be a launching point for other studies that use social network 
analysis to answer and evaluate other international trade related questions. As the world continually becomes linked together through trade ties and political or lawful arrangements, the field and study of SNA becomes more useful in evaluating their relationships and the correlating effects upon one another. The sheer amount of international trade relationships that SNA could apply to are large in scope.

To summarize and conclude, this research embodies a small subset of approaching research questions and topics that SNA imparts distinctive value through its methodological orientation. Existing literature and theories explain why countries choose prospective partners for trade, yet do not fully explain their reasons in relation to each other. When looking at a complex network like one of international trade and bi-lateral trade agreements, looking at the macrocosm instead of the microcosm lends important insight into why and more especially, how this network can change in the future. 


\section{References}

Barber B (1995) All economies are 'embedded': The career of a concept, and beyond. Social Research 62: 387-413

Borjas, George J. (1995) "The Economic Benefits of Immigration," Journal of Economic Literature, Vol. 32 (4), pp. 1667-1717

Borjas, George J. (1995) “The Economic Benefits from Immigration,” Journal of Economic Perspectives, Vol. 9(2), pp.3-22.

Brass, D.J., and M.E. Burkhardt. 1993. "Potential Power and Power Use- An Investigation of Structure and Behavior." Academy of Management Journal 36 (3) 441-70

Burt RS (1987) Social contagion and innovation: Cohesion versus structural equivalence. American Journal of Sociology 92 1287-1335

Clausing, Kimberly A. (2000) “Does Multinational Activity Displace Trade?” Economic Inquiry, Vol. 38(2), pp. 190-205

Cooper Richard N. (2002) "Growth and Inequality: the Role of Foreign Trade and Investment," in the World Bank's Annual Bank Conference on Development Economics 2001/2001. New York: Oxford Uniersity Press., pp103-37

Coppel, Jonathan, Jean-Chirstophe Dumony, and Ignazio Visco (2001) "Trends in Immigration and Economic Consequences,' OECD Working Paper, No. 284

Dunlevy, James A. and William K Hutchinson (1999) "The Impact of Immigration on American Import Trade in the Late Nineteenth and Early Twentieth Centuries," The Journal of Economic History, Vol. 59(3), pp 1043-11062

Dunlevy, James A. and William K. Hutchinson (2001) "The Pro-Trade Effect of Immigration on American Exports During the Late Nineteenth and Early Twentieth Centuries," Institute for Study of Labor Discussion Paper, No. 375 
Friedberg, Rachel M. and Jennifer Hunt (1995) "The Impact of Immigrants on Host Country Wages, Employment, and Growth," Journal of Economic Perspectives, Vol. 9(2), pp.23-44

Girma, Sourafel and Zhihao Yu (2000) "The Link between Immigration and Trade: Evidence from the U.K.," Centre for Research on Globalization and Labour Markets Research Paper, No. 2000/23

Gould, David M. (1994) "Immigrant Links to the Home Country: Empirical Implications for U.S. Bilateral Trade Flows," The Review of Economics and Statistics, Col. 76(2) pp.302-316

Guiso L, (2004) Cultural biases in economic exchange. Kellogg School of Management of Northwestern University Working Paper.

Head, Keith and John Ries (1998) "Immigration and Trade Creation: Econometric Evidence from Canada," Canadian Journal of Economics, Vol. 31(1), pp 47-62

Lee, Bang (2014) "Network Coordination In The Global Goods Flow: The Case of Korea", Journal of International Logistics and Trade, 12(3), pp 3-20

Mansfield E, Milner H (1999) The New Wave of Regionalism. International Organization 53: pp 589-627

Mansfield E, Reinhardt E (2008) International institutions and the volatility of international trade. International Organization 62: 621-652.

Massey, D. S., Durand, J., \& Malone, N. J. (2002). Beyond smoke and mirrors. New York: Russell Sage Foundation, 1945-1990.

Mizruchi MS (1990) Cohension, structural equivalence, and similarity of behavior: A theoretical and empirical assessment. Social Networks 15: 275-307

Mohammad, Cheong (2014) "New Trade Policy of EU: Implication for LDCs", Journal of International Logistics and Trade, 12(1),pp 43-73 
OECD (2002) International Direct Investment Statistics Yearbook, 1989-2000, (Paris: OECD)

Parente, Steph L. and Edward C. Prescott (2000) Barriers to Riches, Cambirdge, MA: MIT Press

Rauch, James E. (1999) "Networks Veresus Markets in International Trade," Journal of International Economics, Vol. 48(1), pp.7-35

Rauch, James E. (2001) "Business and Social Networks," Journal of Economic Literature, Vol. 39(4), pp. 11177-1203

Saxenian, Anna Lee (2002) "Silicon Valley's New Immigrant High-Growth Entrepreneurs," Economic Development Quarterly, Vol. 16(1), pp.20-31.

UNCTAD (2001) World Investment Report, New York: UNCTAD

White HC (2002) Markets from Networks: Socioeconomic Models of Production. Princeton, NJ: Princeton University Press

World Trade Organization (WTO) (2014) International Trade Statistics, Geneva, WTO

Yi, Sang-Seung. (2000). Free-Trade Areas and Welfare: An Equilibrium Analysis. Review of International Economics, 8(2), 336-347.

Zelizer VA (2003) Enter Culture. The New Economic Sociology: Developments in an Emerging Field. New York: Russel Sage Foundation. Pp 101-128. 